\title{
The degree of chemical weathering in the Ba River basin, South Central Vietnam: Major-element geochemistry investigations of morden river sediments and sedimentary rocks
}

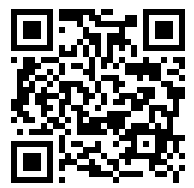

Sang Nhu Pham ${ }^{1,}$, Dung Tien Nguyen ${ }^{1}$, Hung The Khuong ${ }^{1}$, Hien Thanh Thi Pham ${ }^{1}$, Toan Thi Ta ${ }^{1}$, Chinh Cong Thi $\mathrm{Vo}^{2}$

${ }^{1}$ Faculty of Geosciences and Geoengineering, Hanoi University of Mining and Geology, Vietnam

${ }^{2}$ Publishing Office, Hanoi University of Mining and Geology, Vietnam

\section{ARTICLE INFO}

Article history:

Received $16^{\text {th }}$ Nov 2019

Revised $6^{\text {th }}$ Jan. 2020

Accepted $28^{\text {th }}$ Feb. 2020

Keywords:

Chemical weathering,

Major-element geochemistry,

Ba River basin.

\section{ABSTRACT}

Major-element geochemistry of Miocene sedimentary rock and modern river sediment samples in the Ba River basin, South Central Vietnam are utilized to assess the degree of chemical weathering in the Miocene and the present time. Sediment samples were analysed by $X$-ray fluorescence $(X R F)$ spectrometer show that Miocene sedimentary rocks contain higher $\mathrm{SiO}_{2}$ and $\mathrm{K}_{2} \mathrm{O}$, but lower $\mathrm{Fe}_{2} \mathrm{O}_{3}, \mathrm{TiO}_{2}, \mathrm{MgO}, \mathrm{Na}_{2} \mathrm{O}, \mathrm{MnO}, \mathrm{CaO}, \mathrm{P}_{2} \mathrm{O}_{5}$ than modern river sediment. Major-element geochemistry indicates that Miocene sedimentary rocks and modern river sediment are characterized by stronger depliption of $\mathrm{Ca}, \mathrm{Na}$ and $\mathrm{Mg}$ than Kand Si during the chemical weathering in this river basin. The similar relative depleption of $\mathrm{Na}, \mathrm{Ca}$, $\mathrm{Mg}$, Si and $\mathrm{K}$ between modern river sediments and sedimentary rocks indicate not much deffirent the intensity of chemical weathering in the Miocene and the present time. The chemical index of alteration (CIA) alter from 69 to 93 in Miocene sedimentary rocks (average 74) and from 69 to 78 (average 77) in morden river sediments, indicating moderate chemical weathering in the Ba River basin in the Miocene and the present time.

${ }^{*}$ Corresponding author

E-mail: phamnhusang@humg.edu.vn

DOI: 10.46326/JMES.2020.61(1).09 


\section{Tạp chí Khoa học Kỹ thuật Mỏ - Địa chất}

\section{Mức độ phong hóa hóa học ở lưu vực sông Ba, Nam Trung Bộ dựa trên nghiên cứu đặc điểm địa hóa nguyên tố chính trong trầm tích sông hiện đại và đá trầm tích}

\section{Phạm Như Sang1, ${ }^{*}$, Nguyễn Tiến Dũng ${ }^{1}$, Khương Thế Hùng ${ }^{1}$, Phạm Thị Thanh Hiền ${ }^{1}$, Tạ Thị Toán ${ }^{1}$, Võ Thị Công Chính²}

${ }^{1}$ Khoa Khoa hoc và Kỹ thuật Địa chất, Truờng Đại học Mỏ - Đia chất, Việt Nam

${ }^{2}$ Phòng Xuất bản, Trường Đại học Mỏ - Địa chất, Việt Nam

THÔNG TIN BÀI BÁO

Quá trình:

Nhận bài 16/11/2019

Sửa xong $06 / 01 / 2020$

Chấp nhận đăng 28/02/2020

Tù̀ khóa:

Phong hóa hóa học,

Địa hóa nguyên tố chính,

Lưu vực sông Ba.

\section{TÓM TẮT}

Địa hóa nguyên tố chính từ các mẫu đá trầm tích tuổi Miocen và trầm tích sông hiện đại ở lưu vực sông Ba, Nam Trung Bộ, Việt Nam được sử dụng để đánh giá múc độ phong hóa hóa học ở lưu vức này trong Miocen và thời điểm hiện tại. Các mẫu trầm tích được phân tích bằng phương pháp quang phổ huỳnh quang tia X (XRF) cho thấy đá trầm tích Miocen thường chứa $\mathrm{SiO}_{2}$ và $\mathrm{K}_{2} \mathrm{O}$ cao hơn và $\mathrm{Al}_{2} \mathrm{O}_{3}, \mathrm{Fe}_{2} \mathrm{O}_{3}, \mathrm{TiO}_{2}, \mathrm{MgO}, \mathrm{Na}_{2} \mathrm{O}, \mathrm{MnO}, \mathrm{CaO}, \mathrm{P}_{2} \mathrm{O}_{5}$ thấp hơn so với trầm tích sông hiện đại. Số liệu phân tích địa hóa nguyên tố chính trong đá trầm tích Miocen và trầm tích sông hiên đại cho thấy sự di chuyển mạnh mẽ của các nguyên tố Ca, Na và Mg hơn các nguyên tố K và Si trong quá trình phong hóa hóa học. Sự suy giảm tương đối tương đồng của $\mathrm{Na}, \mathrm{Ca}, \mathrm{Mg}$, Si và K trong trầm tích sông hiện đại so với đá trầm tích Miocen cho thấy múc độ phong hóa hóa học trong thời kỳ Miocen và thời điểm hiện tại không có sự khác biệt lớn. Kết quả tính toán cho thấy chỉ số hóa học thay đối (CIA Chemical Index of Alteration) tù̀ $60 \div 93$ (trung bình 74) trong đá trầm tích Miocen và tù̀ $69 \div 78$ (trung bình 77) trong trầm tích sông hiện đại chứng minh múc độ phong hóa hóa học trung bình ở lưu vực sông Ba xảy ra trong giai đoạn Miocen và thời điểm hiện tại.

C 2020 Trường Đại học Mỏ - Địa chất. Tất cả các quyền được bảo đảm.

\section{Mở đầu}

Địa hóa nguyên tố chính của vật liệu trầm tích là sản phẩm của quá trình phong hóa hóa học, chúng có thể cung cấp những thông tin hữu ích về cơ chế cũng như mức độ của quá trình phong hóa

*Tác giả liên hệ

E - mail: phamnhusang@humg.edu.vn

DOI: 10.46326/JMES.2020.61(1).09 hóa học (Galy and France - Lanord, 1999; Singh and et al., 2005; Colin et al., 2006; Liu et al., 2007). Nhiều công trình nghiên cứu ứng dụng địa hóa nguyên tố chính của vật liệu trầm tích trong đánh giá mức độ phong hóa hóa học ở các lưu vực sông xung quanh Biển Đông như sông Châu Giang, sông Hồng, sông Mekong và sông Giành ở Nam Trung Hoa và bán đảo Đông Dương, Philippines, Đài Loan,... đã thu được những thành công nhất định (Liu et al., 2007; Jonell et al., 2016, Selvaraj and Chen, 2006; Wang et al., 2011; Liu et al., 2008, 
2009, 2012; Hu et al., 2014). Nhũng nghiên cứu này chỉ ra rằng, mức độ phong hóa hóa học dao động từ thấp đến trung bình ở Luzon, Philippines (Liu et al., 2009) và các sông nhỏ ở Đài Loan (Liu et al., 2008); mức độ phong hóa trung bình ở sông Châu Giang, sông Hồng, sông Mekong và sông Giành ở Nam Trung Quốc và Việt Nam (Liu et al., 2007; Jonell et al., 2016); trong khi đó ở bán đảo Malay, Borneo và Sumatra có mức độ phong hóa hóa học mạnh mẽ (Wang et al., 2011; Liu et al., 2012). Ở Việt Nam, việc sử dụng địa hóa nguyên tố chính trong các vật liệu trầm tích để xác định mức độ phong hóa hóa học vẫn còn nhiều hạn chế. Các công bố mới chỉ tập trung vào một số tác giả người nước ngoài và tiến hành chủ yếu ở lưu vực sông lớn như sông Hồng và sông Mekong (Liu et al.,
2007). Chính vì vậy, việc tiến hành nghiên cứu địa hóa các nguyên tố chính ở lưu vực sông Ba là thiết thực và cần thiết trong đánh giá mức độ phong hóa hóa học lưu vực sông và nghiên cứu lớp vỏ phong hóa.

Sông Ba có diện tích thoát nước khoảng $14 \times 103$ km², chiều dài 390 km và cung cấp 1 x106 tấn vật liệu trầm tích lơ lửng hàng năm cho Biển Đông (Milliman and Farnsworth, 2011; Hình 1 và 2). Phần thượng lưu của lưu vực sông Ba được đặc trưng bởi một loạt các cao nguyên tiếp giáp với độ cao trung bình khoảng 800 m (vùng Tây Nguyên). Lưu vực này xuất hiện chủ yếu các đá biến chất, đá magma xâm nhập, đá magma phun trào, và đá trầm tích chiếm diện tích nhỏ (Hình 2A). Theo Trần Văn Trị và Vũ Khúc (2009), các đá biến chất được xếp vào tuổi Arkei đến Proterozoi có thành

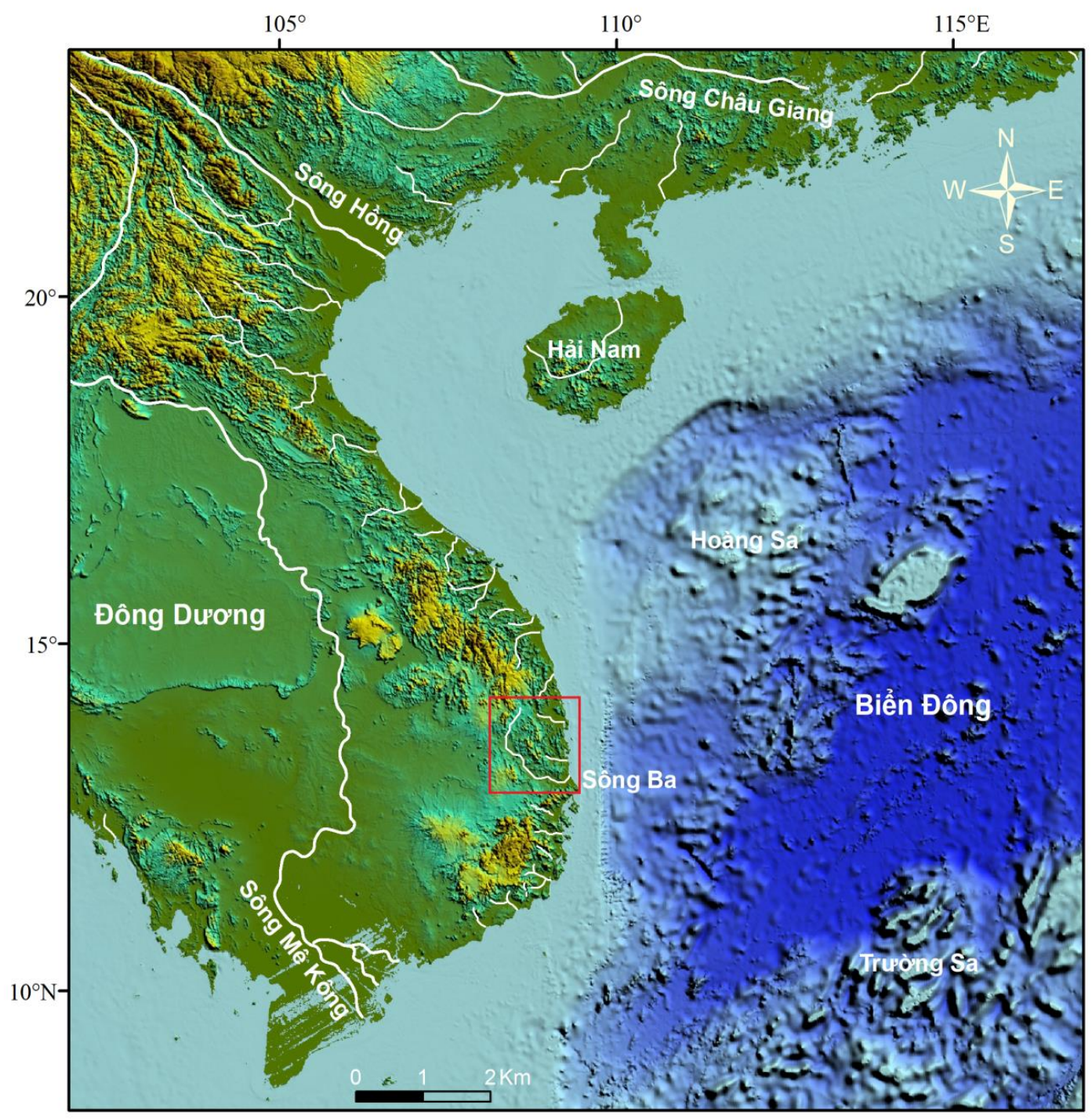

Hình 1. Vị trí luu vực sông Ba ở Nam Trung Bộ, Việt Nam. 


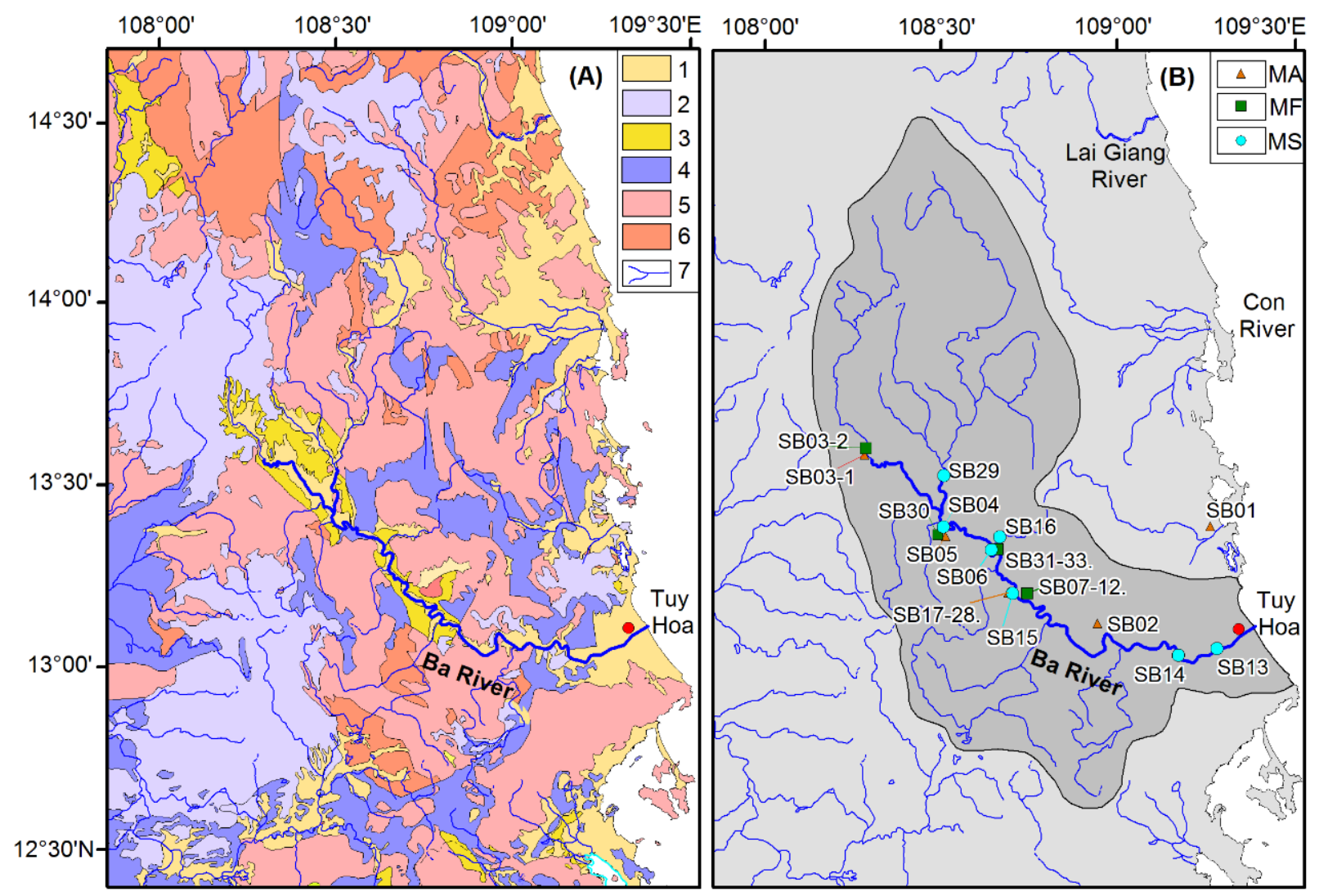

Hình 2. (A) Sơ đồ địa chất lưu vực sông Ba, Nam Trung Bộ, Việt Nam được chỉnh sứa tù̀ bản đồ địa chất 1:500.000 (Trần Đức Lương, Nguyễn Xuân Bao, 1988). 1. Trầm tích Holocen; 2. Đá basal tuổi Neogen - Đệ Tú; 3. Đá trầm tích tuổi Miocen; 4. Đá phun trào tuổi Mesozoi; 5. Đá xâm nhập felsic tuổi Paleo - Mesozoi; 6. Đá biến chất tuổi tiền Cambrian; 7. Sông. (B) Vị trí mẫu sử dụng trong nghiên cúu. MA. Mẫu đá trầm tích Miocen chứa nhiều andesit và ryolit; MF. Mẫu đá trầm tích Miocen chứa nhiều felsic; MS. Mẫu trầm tích sông.

phần khác nhau; các đá xâm nhập granit, granodiorit và diorit được xếp vào tuổi Paleozoi sớm đến Mesozoi (Trần Đức Lương, Nguyễn Xuân Bao, 1988; Nam, 1998; Lan et al., 2003; Nakano et al., 2007; Lepvrier et al., 2008). Các đá phun trào có thành phần chủ yếu là andesit, ryolit, dacit và felsit tuổi Trias sớm và tuổi Kreta, chúng phủ rộng rãi ở khu vực nghiên cứu (Nam et al., 2001). Đá trầm tích Miocen chứa đá cuội, đá silic, đá sét và than xuất hiện hạn chế dọc theo sông Ba trong Miocen giữa và muộn (Nielsen et al., 2007). Khu vực này, đá bazan xuất hiện và bao phủ có tuổi Neogen - Đệ tứ (Hoang and Flower, 1998; Carter et al., 2000; Hoang et al., 2013). Dọc theo sông và bờ biển phát triển chủ yếu các trầm tích Holocen.

Trong bài báo này, địa hóa nguyên tố chính của các đá trầm tích Miocen và trầm tích sông hiện đại được thu thập từ lưu vực sông Ba ở khu vực Nam Trung Bộ để đánh giá mức độ phong hóa hóa học trong Miocen và thời điểm hiện tại.

\section{Cơ sở tài liệu và phương pháp}

Tổng cộng 27 mẫu đá trầm tích Miocen (hệ tầng Sông Ba) được thu thập ở lưu vực sông Ba và dựa vào thành phần vật liệu trầm tích, chúng được phân chia thành hai loại như sau: (1) mẫu đá trầm tích Miocen andesit (thành phần chủ yếu có nguồn gốc từ đá phun trào andesit và ryolit - MA); (2) mẫu đá trầm tích Miocen felsic (thành phần chủ yếu có nguồn gốc từ đá xâm nhập felsic - MF) (Bảng 1, Hình 2B). Mẫu đá trầm tích Miocen được lấy từ hệ tầng sông Ba tại những diện lộ của chúng dọc theo sông Ba và lấy phần chưa bị phong hóa. Tại các vị trí khác nhau dọc theo sông $\mathrm{Ba}, 07$ mẫu trầm tích sông hiện đại (MS) được thu thập để đại diện cho các trầm tích của lưu vực này (Bảng 1 , Hình 2B). 
Các mẫu trầm tích này được lấy ở bề mặt trầm tích dọc theo hệ thống sông Ba và tránh sự ô nhiễm cũng như tác động từ hoạt động của con người. Trong số đó, hai mẫu (SB13 và SB14) từ phần thấp hơn của kênh chính đại diện cho các thành phần trung lưu của trầm tích sông $\mathrm{Ba}$; ba mẫu (SB04, SB06 và SB15) từ kênh chính và hai mẫu khác (SB16 và SB29) từ nhánh của phạm vi trung lưu đại diện cho môi trường trung lưu của lưu vực sông Ba. Máy huỳnh quang tia X - XRF (PANalytical AxiosmAX wavelength dispersive X ray Fluorescence (XRF) spectrometer) được sử dụng để phân tích thành phần nguyên tố chính của tất cả các mẫu đá trầm tích và trầm tích sông tai Phòng thí nghiệm của Trường Đại học Đồng Tế, Thượng Hải, Trung Quốc.

Bảng 1. Thành phần nguyên tố chính trong mẫu đá trầm tích Miocen và mẫu trầm tích sông hiện đại ở lư vực sông $B a$.

\begin{tabular}{|c|c|c|c|c|c|c|c|c|c|c|c|c|}
\hline STT & Mẫu & $\mathrm{Al}_{2} \mathrm{O}_{3}$ & $\mathrm{CaO}$ & $\mathrm{Fe}_{2} \mathrm{O}_{3}$ & $\mathrm{~K}_{2} \mathrm{O}$ & $\mathrm{MgO}$ & $\mathrm{MnO}$ & $\mathrm{Na}_{2} \mathrm{O}$ & $\mathrm{P}_{2} \mathrm{O}_{5}$ & $\mathrm{TiO}_{2}$ & $\mathrm{SiO}_{2}$ & CIA \\
\hline \multicolumn{13}{|c|}{ Mẫu đá trầm tích Miocen andesit (MA) } \\
\hline 1 & SB01 & 14,60 & 0,145 & 2,54 & 3,29 & 0,64 & 0,01 & 0,40 & 0,03 & 0,56 & 74,43 & 77 \\
\hline 2 & SB02 & 17,14 & 0,606 & 4,52 & 2,54 & 1,35 & 0,08 & 1,17 & 0,02 & 0,50 & 67,19 & 75 \\
\hline 3 & SB03 - 2 & 29,81 & 0,326 & 3,18 & 1,86 & 0,59 & 0,01 & 0,12 & 0,02 & 0,50 & 61,97 & 93 \\
\hline 4 & SB05 & 18,64 & 1,561 & 4,13 & 1,94 & 0,59 & 0,01 & 0,60 & 0,02 & 0,76 & 70,48 & 82 \\
\hline 5 & SB17 & 11,92 & 0,278 & 1,06 & 3,76 & 0,35 & 0,01 & 0,96 & 0,02 & 0,27 & 79,12 & 66 \\
\hline 6 & SB18 & 16,20 & 0,417 & 1,87 & 3,51 & 0,51 & 0,02 & 0,92 & 0,02 & 0,60 & 74,14 & 73 \\
\hline 7 & SB19 & 12,38 & 0,314 & 1,25 & 4,36 & 0,34 & 0,02 & 1,49 & 0,02 & 0,26 & 75,54 & 62 \\
\hline 8 & SB20 & 16,80 & 0,46 & 1,87 & 3,43 & 0,52 & 0,01 & 0,95 & 0,02 & 0,63 & 71,49 & 73 \\
\hline 9 & SB21 & 14,04 & 0,336 & 1,51 & 4,03 & 0,44 & 0,02 & 1,22 & 0,01 & 0,38 & 74,82 & 67 \\
\hline 10 & SB22 & 10,23 & 0,274 & 1,58 & 3,84 & 0,27 & 0,02 & 1,38 & 0,04 & 0,20 & 77,29 & 60 \\
\hline 11 & SB23 & 13,79 & 0,32 & 1,28 & 3,85 & 0,39 & 0,02 & 1,58 & 0,02 & 0,35 & 74,36 & 65 \\
\hline 12 & SB24 & 15,98 & 0,373 & 2,00 & 3,66 & 0,60 & 0,02 & 1,27 & 0,03 & 0,60 & 70,99 & 71 \\
\hline 13 & SB25 & 14,48 & 0,246 & 1,13 & 4,22 & 0,28 & 0,01 & 1,16 & 0,01 & 0,26 & 74,31 & 68 \\
\hline 14 & SB26 & 13,16 & 0,197 & 0,87 & 3,81 & 0,24 & 0,01 & 1,01 & 0,01 & 0,28 & 77,12 & 68 \\
\hline 15 & SB27 & 16,13 & 0,333 & 1,38 & 3,91 & 0,35 & 0,01 & 0,92 & 0,01 & 0,53 & 71,75 & 72 \\
\hline 16 & SB28 & 15,73 & 0,27 & 1,56 & 4,19 & 0,29 & 0,01 & 0,98 & 0,02 & 0,28 & 72,86 & 70 \\
\hline \multicolumn{13}{|c|}{ Mẫu đá trầm tích Miocen felsic (MF) } \\
\hline 17 & SB03-1 & 30,09 & 0,439 & 2,22 & 2,14 & 0,41 & 0,01 & 0,09 & 0,03 & 0,61 & 62,71 & 92 \\
\hline 18 & SB07 & 22,54 & 0,173 & 4,39 & 2,77 & 0,34 & 0,01 & 0,27 & 0,03 & 0,79 & 66,21 & 86 \\
\hline 19 & SB08 & 12,04 & 0,219 & 1,43 & 3,82 & 0,20 & 0,01 & 0,15 & 0,02 & 0,75 & 80,16 & 72 \\
\hline 20 & SB9 & 17,96 & 0,227 & 3,82 & 3,09 & 0,31 & 0,01 & 0,32 & 0,03 & 0,68 & 71,71 & 81 \\
\hline 21 & SB10 & 16,22 & 0,187 & 0,82 & 3,97 & 0,29 & 0,01 & 0,20 & 0,02 & 0,57 & 76,68 & 77 \\
\hline 22 & SB11 & 13,57 & 0,161 & 0,69 & 4,04 & 0,25 & 0,01 & 0,19 & 0,01 & 0,34 & 79,33 & 73 \\
\hline 23 & SB12 & 19,73 & 0,268 & 1,88 & 3,49 & 0,38 & 0,01 & 0,26 & 0,02 & 0,61 & 72,17 & 81 \\
\hline 24 & SB30 & 8,54 & 0,077 & 1,06 & 3,08 & 0,15 & 0,01 & 0,09 & 0,00 & 0,28 & 85,24 & 70 \\
\hline 25 & SB31 & 11,35 & 0,099 & 0,56 & 2,92 & 0,19 & 0,01 & 0,13 & 0,01 & 0,70 & 82,43 & 76 \\
\hline 26 & SB32 & 13,21 & 0,203 & 1,22 & 4,23 & 0,26 & 0,01 & 0,21 & 0,01 & 0,31 & 78,80 & 71 \\
\hline 27 & SB33 & 15,07 & 0,188 & 0,75 & 5,17 & 0,23 & 0,01 & 0,20 & 0,02 & 0,46 & 76,42 & 71 \\
\hline \multicolumn{13}{|c|}{ Mẫu trầm tích sông (MS) } \\
\hline 28 & SB04 & 18,45 & 1,299 & 7,98 & 2,59 & 1,20 & 0,18 & 0,99 & 0,24 & 1,51 & 56,72 & 75 \\
\hline 29 & SB06 & 14,85 & 0,89 & 3,94 & 3,19 & 0,67 & 0,12 & 0,96 & 0,13 & 0,80 & 67,40 & 70 \\
\hline 30 & SB13 & 16,50 & 1,088 & 4,33 & 3,04 & 0,75 & 0,15 & 1,32 & 0,19 & 0,82 & 61,53 & 70 \\
\hline 31 & SB14 & 18,78 & 1,00 & 6,94 & 2,55 & 0,97 & 0,24 & 0,83 & 0,21 & 1,08 & 60,32 & 78 \\
\hline 32 & SB15 & 16,41 & 0,868 & 4,87 & 3,38 & 0,73 & 0,15 & 1,03 & 0,14 & 0,99 & 66,73 & 71 \\
\hline 33 & SB16 & 18,44 & 1,128 & 5,83 & 3,33 & 0,88 & 0,29 & 1,73 & 0,13 & 0,87 & 62,90 & 69 \\
\hline 34 & SB29 & 17,31 & 0,877 & 4,90 & 3,84 & 0,73 & 0,10 & 1,29 & 0,15 & 1,01 & 63,60 & 70 \\
\hline
\end{tabular}


Các nguyên tố chính được phân tích bằng cách sử dụng máy quang phổ huỳnh quang tia X. Các mẫu được sấy khô và nghiền thành bột mịn bằng cách sử dụng cối đá mã não. Mỗi mẫu sau đó được tạo ra để đảm bảo rằng mẫu bột được trộn đều và sau đó được nén bằng bột axit boric $\left(\mathrm{H}_{3} \mathrm{BO}_{3}\right)$ vào một đĩa để phân tích. Axit boric được sử dụng làm lớp phủ bên ngoài mẫu trầm tích. Các mẫu tiêu chuẩn của đá trầm tích và trầm tích GSR06 và GSD15 được sử dụng để kiểm soát độ chính xác phân tích. Các oxit nguyên tố chính $\mathrm{SiO}_{2}, \mathrm{Al}_{2} \mathrm{O}_{3}$, $\mathrm{Fe}_{2} \mathrm{O}_{3}, \mathrm{MgO}, \mathrm{CaO}, \mathrm{K}_{2} \mathrm{O}, \mathrm{Na}_{2} \mathrm{O}, \mathrm{P}_{2} \mathrm{O}_{5}, \mathrm{TiO}_{2}$ và $\mathrm{MnO}$ được phân tích trong phương pháp này.

\section{Kết quả}

Thành phần nguyên tố chính của các mẫu đá trầm tích Miocen andesit (MA), mẫu đá trầm tích Miocen felsic (MF) và mẫu trầm tích sông hiện đại (MS) chứa chủ yếu là $\mathrm{SiO}_{2}$ và $\mathrm{Al}_{2} \mathrm{O}_{3}$ (tổng hàm lượng trung bình $88 \%$ ), và hàm lượng nhỏ các oxit $\mathrm{K}_{2} \mathrm{O}, \mathrm{Fe}_{2} \mathrm{O}_{3}, \mathrm{Na}_{2} \mathrm{O}, \mathrm{MgO}, \mathrm{CaO}, \mathrm{P}_{2} \mathrm{O}_{5}, \mathrm{TiO}_{2}$ và $\mathrm{MnO}$ (tổng hàm lượng trung bình 8,5\%) (Bảng 1 ). Kết quả phân tích thành phần nguyên tố chính cho thấy đá trầm tích Miocen thường chứa $\mathrm{SiO}_{2}$ và $\mathrm{K}_{2} \mathrm{O}$ cao hơn và $\mathrm{Al}_{2} \mathrm{O}_{3}, \mathrm{Fe}_{2} \mathrm{O}_{3}, \mathrm{Na}_{2} \mathrm{O}, \mathrm{MgO}, \mathrm{CaO}, \mathrm{P}_{2} \mathrm{O}_{5}$, $\mathrm{TiO}_{2}$ và $\mathrm{MnO}$ thấp hơn so với trầm tích sông hiện đại.

\section{Thảo luận}

Trong quá trình phong hóa hóa học, các nguyên tố linh động như $\mathrm{K}$, Na và Ca dần bị thoát ra từ đá gốc, nhưng các nguyên tố khác như $\mathrm{Al}, \mathrm{Fe}$ và Ti được làm giàu trong các sản phẩm phong hóa (Nesbitt et al., 1980). Do đó, thành phần nguyên tố chính của các sản phẩm phong hóa của đá silicat có thể được sử dụng để xác định con đường thay đổi và đánh giá sự phong hóa hóa học trong lưu vực sông (Nesbitt et al., 1980; Vital and Stattegger, 2000; Dessert et al., 2001; Singh et al., 2005). Để xác định và đánh giá tính linh động của các nguyên tố chính, nghiên cứu sử dụng các tỷ lệ nguyên tố được tính tương ứng với phần tử di động ít nhất $\mathrm{Al}$. Các tỷ lệ của hàm lượng nguyên tố $\mathrm{X}$ và $\mathrm{Al}_{2} \mathrm{O}_{3}$ trong các mẫu nghiên cứu chia cho tỷ lệ của cùng một nguyên tố trong lớp vỏ lục địa phía trên (UCC - Upper Continental Crust) (Singh et al., 2005).

$$
\text { Tỷ lệ nguyên tố }(X)=\frac{X / A l_{2} O_{3}(m a ̂ ̃ u)}{X / A l_{2} O_{3}(U C C)}
$$

Tỷ lệ này đề cập đến sự làm giàu tương đối hoặc sự suy giảm của một nguyên tố, > 1 biểu thị sự làm giàu, $<1$ biểu thị sự suy giảm và $=1$ cho thấy không có sự thay đổi nào (Singh et al., 2005).

Tỷ lệ nguyên tố trung bình của mẫu đá trầm tích Miocen andesit và mẫu đá trầm tích Miocen felsic cho thấy độ linh động hóa học tương đối giống nhau (Hình 3). Tuy nhiên, các nguyên tố chính từ hai loại mẫu đá trầm tích Miocen thể hiện tính linh động khác nhau với các mẫu trầm tích sông hiện đại. Các mẫu đá trầm tích Miocen bị suy giảm mạnh ở tất cả các nguyên tố chính so với các mẫu trầm tích sông hiện đại, ngoại trừ $S i$ và $K$, ngụ ý rằng đá trầm tích Miocen có thể chứa các khoáng vật có hàm lượng $\mathrm{Si}$ và $\mathrm{K}$ cao (ví dụ: thạch anh, mica và $\mathrm{K}$ - feldspar). Ngoài ra, các mẫu đá trầm tích Miocen cho thấy tỷ lệ nguyên tố $\mathrm{Ca}, \mathrm{Mg}$ và $\mathrm{Na}$ thấp hơn so với các mẫu trầm tích sông hiện đại, cho thấy đá trầm tích Miocen được cung cấp nhiều từ vật liệu của đá felsic (đá xâm nhập felsic tuổi Paleo - Mesozoi và đá phun trào tuổi Mesozoic) hơn là trầm tích sông. Ti và $\mathrm{Mn}$ được làm giàu, $\mathrm{Fe}$ ổn định và $\mathrm{P}$ bị thoát đi một chút trong các mẫu trầm tích sông hiện đại, trong khi tất cả các nguyên tố này bị giảm đi trong các mẫu đá trầm tích Miocen, chỉ ra rằng trầm tích sông hiện đại có chứa khoáng vật giàu sắt. Nhưng kết luận này rất phù hợp với sự xuất hiện của đá gốc trong lưu vực sông Ba. Đá trầm tích Miocen chỉ có thể được tạo ra từ các vật liệu của đá biến chất Precambrian, đá xâm nhập felic Paleo - Mesozoi và đá phun trào Mesozoi, trong khi trầm tích sông hiện đại có thể được cung cấp từ các vật liệu không chỉ từ những loại đá này mà còn từ đá trầm tích tuổi Miocen và đá basalt tuổi Neogen và Đệ Tứ (Hình 2A). Trong khu vực nghiên cứu này, cường độ suy giảm các nguyên tố chính như sau: $\mathrm{Ca}>\mathrm{P}>\mathrm{Mg}>\mathrm{Na}>\mathrm{Mn}>$ $\mathrm{Fe}>\mathrm{Ti}>\mathrm{K}>$ Si đối với các mẫu đá trầm tích Miocen và $\mathrm{Ca}>\mathrm{Na}>\mathrm{Mg}>\mathrm{P}>\mathrm{K}>\mathrm{Si}>\mathrm{Fe}>\mathrm{Ti}>\mathrm{Mn}$ cho các mẫu trầm tích sông hiện đại. Điều này cho thấy các nguyên tố kim loại kiềm (Na) và kim loại kiềm thổ (Ca, $\mathrm{Mg}$ ) dễ bị di chuyển từ đá gốc trong quá trình phong hóa hóa học hơn các nguyên tố chính khác. Theo sự suy giảm mạnh của $\mathrm{Na}$, Ca và $\mathrm{Mg}$ trong tất cả các mẫu cùng với sự di chuyển ít của $S i$ và $K$ trong các mẫu trầm tích sông hiện đại và hàm lượng $\mathrm{Si}$ và $\mathrm{K}$ ổn định trong các mầu đá trầm tích Miocen cho thấy sự khác biệt của mức độ phong hóa hóa học trong thời kỳ Miocen và thời điểm hiện tại là không đáng kể ở lưu vực sông Ba. 


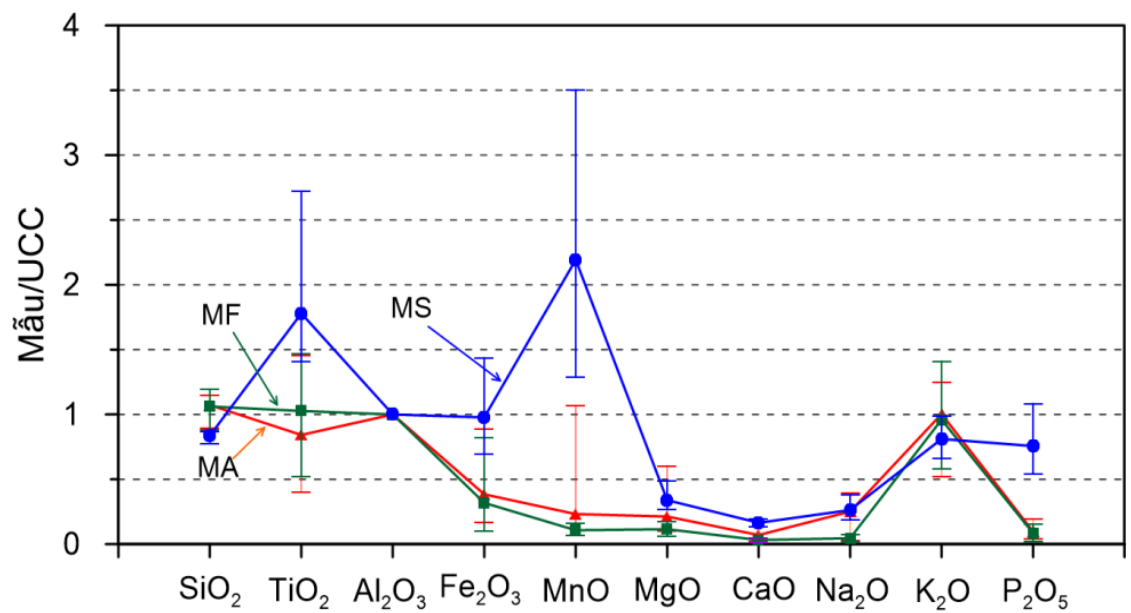

Hình 3. Tỷ lệ nguyên tố chính của các mẫu đá trầm tích Miocen andesit (MA), đá trầm tích Miocen felsic (MF) và trầm tích sông hiện đại (MS) ở lưu vực sông Ba được tính toán tù giá trị trung bình của thành phần nguyên tố chính trong lóp vỏ lục địa phía trên (Upper continental crust - UCC) (Taylor and McLennan, 1985) với Al203. Các thanh giá trị của mỗi oxit chỉ ra độ lệch chuẩn của tất cả các mẫu.

Sự thay đổi chỉ số hóa học (CIA - Chemical Index of Alteration) được sử dụng để đánh giá mức độ phong hóa hóa học (Nebitt Young, 1982). CIA đã được sử dụng bởi nhiều nghiên cứu trước đó (McLennan, 1993; Galy and France - Lanord, 1999; Singh et al., 2005; Selvaraj and Chen, 2006; Liu et al., 2007). Các giá trị CIA được tính như công thức (Nesbitt and Young, 1982):

$$
\mathrm{CIA}=\left[\mathrm{Al}_{2} \mathrm{O}_{3} /\left(\mathrm{Al}_{2} \mathrm{O}_{3}+\mathrm{CaO}^{*}+\mathrm{Na}_{2} \mathrm{O}+\mathrm{K}\right)\right] \times 100
$$

Trong đó: $\mathrm{CaO}^{*}$ là lượng $\mathrm{CaO}$ được kết hợp trong phần silicat của đá gốc (Nesbitt and Young, 1989; Nesbitt et al., 1996). Dựa trên sự suy giảm của các nguyên tố di động như $\mathrm{Na}, \mathrm{Ca}$ và $\mathrm{K}$ với nguyên tố không di chuyển $\mathrm{Al}$, các giá trị CIA được tính toán để đánh giá mức độ phong hóa hóa học cho các loại đá (Nesbitt and Young, 1982). Giá trị CIA trong khoảng $45 \div 55$ cho thấy quá trình phong hóa hóa học chưa diễn ra, giá trị CIA $<60$ phong hóa hóa học yếu, CIA = 60 - 80 phong hóa hóa học trung bình và CIA > 80 quá trình phong hóa hóa học mạnh.

Kết quả tính toán cho thấy giá trị CIA từ

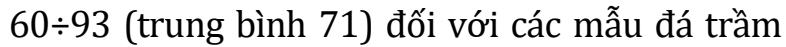

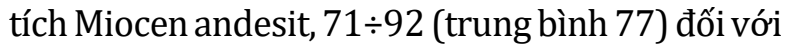
các mẫu đá trầm tích Miocen felsic và $69 \div 78$ (trung bình 72 ) đối với các mẫu trầm tích sông hiện đại (Bảng 1). Hai loại mẫu đá trầm tích Miocen cho thấy sự thay đổi lớn hơn về giá trị CIA so với trầm tích sông hiện đại. Thông thường, đá núi lửa bị phong hóa dễ dàng hơn đá xâm nhập và có giá trị CIA cao hơn trong các sản phẩm phong hóa. Tuy nhiên, mẫu đá trầm tích Miocen andesit cho thấy giá trị CIA trung bình thấp hơn 6 giá trị so với mẫu đá trầm tích Miocen felsic. Điều này có thể gây ra bởi độ tuổi khác nhau của đá gốc, vì các sản phẩm phong hóa của đá có tuổi già hơn có thể bị phong hóa lâu hơn. Tuy nhiên, giá trị trung bình của CIA không khác biệt lớn giữa các mẫu đá trầm tích Miocen andesit (trung bình 71) và các mẫu đá trầm tích Miocen felsic (trung bình 77), cho thấy mức độ phong hóa hóa học ở khu vực này không bị ảnh hưởng mạnh bởi nguồn gốc vật liệu. Những điều trên cho thấy quá trình phong hóa hóa học xảy ra ở mức độ vừa phải trong Miocen cũng như trong thời điểm hiện tại. Trong thời kỳ Miocen, mức độ phong hóa hóa học cao hơn so với thời điểm hiện tại. Điều này có thể tương ứng với điều kiện khí hậu ấm hơn trong Miocen so với thời điểm hiện tại (Wei et al., 2006; Wan et al., 2007). Để có cái nhìn tổng quát về quá trình phong hóa hóa học xung quanh Biển Đông, dữ liệu trầm tích sông hiện đại của lưu vực sông Ba được so sánh với dữ liệu từ các khu vực lân cận xung quanh Biển Đông. Ở lưu vực sông Ba, cường độ phong hóa hóa học hiển thị ở mức độ thấp hơn so với sông Châu Giang (Liu et al., 2007) và sông ở Sumatra (Liu et al., 2012), những khu vực này phong hóa hóa học diễn ra mạnh mẽ. Mặt khác, lưu vực sông Ba cho thấy mức độ phong hóa hóa học khá tương đồng như ở sông Mekong và sông Hồng (Liu et al., 2007), khu vực này có mức độ phong hóa hóa học vừa phải. Tuy nhiên, khu vực nghiên cứu có mức độ phong hóa hóa học mạnh hơn nhiều so với các 
sông ở Đài Loan (Selvaraj and Chen, 2006; Liu et al., 2008) và Luzon (Liu et al., 2009), nơi có mức độ phong hóa hóa học từ yếu đến trung bình.

\section{Kết luận}

Địa hóa nguyên tố chính từ các đá trầm tích Miocen và trầm tích sông hiện đại trong lưu vực sông Ba, Nam Trung Bộ được nghiên cứu để ước lượng mức độ phong hóa hóa học của khu vực này trong Miocen và thời điểm hiện tại. Từ kết quả nghiên cứu có thể đưa ra những kết luận sau:

Các đá trầm tích Miocen và trầm tích sông hiện đại được đặc trưng bởi hàm lượng $\mathrm{SiO}_{2}$ và $\mathrm{Al}_{2} \mathrm{O}_{3}$ cao (tổng hàm lượng trung bình $88 \%$ ), và $\mathrm{K}_{2} \mathrm{O}$, $\mathrm{Fe}_{2} \mathrm{O}_{3}, \mathrm{Na}_{2} \mathrm{O}, \mathrm{MgO}, \mathrm{CaO}, \mathrm{P}_{2} \mathrm{O}_{5}, \mathrm{TiO}_{2}$ và $\mathrm{MnO}$ thấp (tổng hàm lượng trung bình $8,5 \%$ ). Các đá trầm tích Miocen thường chứa $\mathrm{SiO}_{2}$ và $\mathrm{K}_{2} \mathrm{O}$ cao hơn, trong khi đó $\mathrm{Al}_{2} \mathrm{O}_{3}, \mathrm{Fe}_{2} \mathrm{O}_{3}, \mathrm{TiO}_{2}, \mathrm{MgO}, \mathrm{Na}_{2} \mathrm{O}, \mathrm{MnO}$, $\mathrm{CaO}$ và $\mathrm{P}_{2} \mathrm{O}_{5}$ thấp hơn so với trầm tích sông hiện đại.

Kết quả phân tích tỷ lệ nguyên tố cho thấy, sự di chuyển đầu tiên của các nguyên tố $\mathrm{Ca}, \mathrm{Na}$ và $\mathrm{Mg}$ sau đó là các nguyên tố $K$ và $S i$ trong quá trình phong hóa hóa học ở lưu vực sông Ba. Sự suy giảm của $\mathrm{Na}, \mathrm{Ca}, \mathrm{Mg}$, Si và $\mathrm{K}$ trong tất cả các mẫu trầm tích sông hiện đại và đá trầm tích Miocen không có sự khác biệt lớn, cho thấy mức độ phong hóa hóa học trong thời kỳ Miocen và thời điểm hiện tại là khá tương đồng.

Kết quả tính toán chỉ số hóa học (CIA) cho thấy, CIA thay đổi trong khoảng $60 \div 93$ (trung bình 71) đối với các mẫu đá trầm tích Miocen andesit, $71 \div 92$ (trung bình 77) đối với các mẫu đá trầm tích Miocen felsic và 69:78 (trung bình 72 ) đối với các mẫu trầm tích sông hiện đại. Chỉ số hóa học này đã chứng minh mức độ phong hóa hóa học trung bình trong cả Miocen và thời điểm hiện tại ở lưu vực sông Ba, Nam Trung Bộ.

\section{Lò̀i cảm on}

Nhóm tác giả xin gửi lời cảm ơn giáo sư Liu Zhifei, tiến sĩ Yan Lili cùng các cán bộ phòng phân tích Trường Đại học Đồng Tế, Trung Quốc đã giúp đỡ nhóm nghiên cứu trong quá trình phân tích mẫu. Nhóm nghiên cứu xin cảm ơn sự giúp đỡ và tạo điều kiện vô cùng quý báu của các thầy cô trong Bộ môn Tìm kiếm - Thăm dò, Khoa Khoa học và Kỹ thuật Địa chất, các Phòng Ban chức năng của Nhà Trường đã tạo điều kiện thuận lợi cho quá trình nghiên cứu của nhóm tác giả. Kết quả nghiên cứu được sự hỗ trợ từ Đề tài nghiên cứu cấp cơ sở mã số T18 - 34 của Trường Đại học Mỏ - Địa chất.

\section{Tài liệu tham khảo}

Carter, A., Roques, D., Bristow, C. S., (2000). Denudation history of onshore central Vietnam: Constraints on the Cenozoic evolution of the western margin of the South China Sea. Tectonophysics 322, 265-277.

Colin, C., Turpin, L., Blamart, D., Frank, N., Kissel, C., Duchamp, S., (2006). Evolution of weathering patterns in the Indo - Burman Ranges over the last 280 kyr: Effects of sediment provenance on $87 \mathrm{Sr} / 86 \mathrm{Sr}$ ratios tracer. Geochem. Geophys. Geosyst. 7, 1-16.

Dessert, C., Dupre, B., Francois, L. M., Schott, J., Gaillardet, J., Chakrapani, G., Bajpai, S., (2001). Erosion of Deccan Traps determined by river geochemistry: Impact on the global climate and the $87 \mathrm{Sr} / 86 \mathrm{Sr}$ ratio of seawater. Earth Planet. Sci. Lett. 188, 459-474.

Galy, A., France - Lanord, C., 1999. Weathering processes in the Ganges - Brahmaputra basin and the riverine alkalinity budget. Chem. Geol. $159,31-60$.

Hoang, N., Flower, M., (1998). Petrogenesis of Cenozoic Basalts from Vietnam: Implication for Origins of a Diffuse Igneous Province. J. Petrol. 39, 369-395.

Hoang, N., Flower, M. F. J., Chi, C. T., Xuan, P. T., Quy, H.V., Son, T.T., (2013). Collision - induced basalt eruptions at Pleiku and Buon Me Thuat, south - central Viet Nam. J. Geodyn. 69, 65-83.

Hu, B., Li, J., Cui, R., Wei, H., Zhao, J., Li, G., Fang, X., (2014). Clay mineralogy of the riverine sediments of Hainan Island, South China Sea: Implications for weathering and provenance.J. Asian Earth Sci. 96, 84-92.

Jonell, T. N., Clift, P. D., Hoang, L. V., Hoang, T., Carter, A., Wittmann, H., Böning, P., Pahnke, K., Rittenour, T., (2016). Controls on erosion patterns and sediment transport in a monsoonal, tectonically quiescent drainage, Song Gianh, central Vietnam. Basin Res. 29, 125. 
Lan, C., Chung, S., Long, T. Van, Lo, C., Lee, T., Mertzman, S. A., Shen, J. J., (2003). Geochemical and $\mathrm{Sr}$ - $\mathrm{Nd}$ isotopic constraints from the Kontum massif, central Vietnam on the crustal evolution of the Indochina block. Precambrian Res. 122, 7-27.

Lepvrier, C., Vuong, N. V., Maluski, H., Thi, P. T., Vu, T.V., (2008). Indosinian tectonics in Vietnam. Comptes Rendus - Geosci. 340, 94-111.

Liu, Z., Colin, C., Huang, W., Phon, L. K., Tong, S., Chen, Z., Trentesaux, A., (2007). Climatic and tectonic controls on weathering in south China and Indochina Peninsula: Clay mineralogical and geochemical investigations from the Pearl, Red, and Mekong drainage basins. Geochem. Geophys. Geosyst. 8, 1-18.

Liu, Z., Tuo, S., Colin, C., Liu, J. T., Huang, C. Y., Selvaraj, K., Chen, C. T. A., Zhao, Y., Siringan, F. P., Boulay, S., Chen, Z., (2008). Detrital fine grained sediment contribution from Taiwan to the northern South China Sea and its relation to regional ocean circulation. Mar. Geol. 255, 149-155.

Liu, Z., Zhao, Y., Colin, C., Siringan, F. P., Wu, Q., (2009). Chemical weathering in Luzon, Philippines from clay mineralogy and major element geochemistry of river sediments. Appl. Geochem. 24, 2195-2205.

Liu, Z., Wang, H., Hantoro, W. S., Sathiamurthy, E., Colin, C., Zhao, Y., Li, J., (2012). Climatic and tectonic controls on chemical weathering in tropical Southeast Asia (Malay Peninsula, Borneo, and Sumatra). Chem. Geol. 291, 1-12.

McLennan, S. M., (1993). Weathering and Global Denudation.J. Geol. 101, 295-303.

Milliman, J. D., Farnsworth, K. L., (2011). River Discharge to the Coastal Ocean: A Global Synthesis, Cambridge University Press, Cambridge, 382p.

Nakano, N., Osanai, Y., Owada, M., Nam, T. N., Toyoshima, T., Binh, P., Tsunogae, T., Kagami, H., (2007). Geologic and metamorphic evolution of the basement complexes in the Kontum Massif, central Vietnam. Gondwana Res. 12, 438-453.

Nam, T. N., (1998). Thermotectonic events from
Eparly Proterozoic to Miocen in the Indochina craton: Implication of $\mathrm{K}$ - Ar ages in Vietnam. J. Asian Earth Sci. 16, 475-484.

Nam, T. N., Sano, Y., Terada, K., Toriumi, M., Quynh, P. V., Dung, L. T., (2001). First SHRIMP U - Pb zircon dating of granulites from the Kontum massif (Vietnam) and tectonothermal implications. J. Asian Earth Sci. 19, 77-84.

Nesbitt, H. W., Markovics, G., Price, R. C., (1980). Chemical processes affecting alkalis and alkaline Earth during continental weathering. Geochim. Cosmochim. Acta 44, 1659-1666.

Nebitt, H. W., Young, G. M., (1982). Early Proterozoic climates and plate motions inferred from major element chemistry of lutites. Nature 299, 715-717.

Nesbitt, H. W., Young., G. M., (1989). Formation and diagenesis of weathering profiles. J. Geol. 97, 129-147.

Nesbitt, H. W., Young, G. M., McLennan, S. M., Keays, R. R., (1996). Effects of Chemical Weathering and Sorting on the Petrogenesis of Siliciclastic Sediments, with Implications for Provenance Studies. J. Geol. 104, 525-542.

Nielsen, L. H., Petersen, H. I., Thai, N. D., Duc, N. A., Fyhn, M. B. W., Boldreel, L. O., Tuan, H. A., Lindstrom, S., Hien, L. V., (2007). A Middle Upper Miocen fluvial - lacustrine rift sequence in the Song Ba Rift, Vietnam: an analogue to oil - prone, small - scale continental rift basins. Pet. Geosci. 13, 145-168.

Selvaraj, K., Chen, C. A., (2006). Moderate Chemical Weathering of Subtropical Taiwan: Constraints from Solid - Phase Geochemistry of Sediments and Sedimentary Rocks. J. Geol. 114, 101-116.

Singh, M., Sharma, M., Tobschall, H. J., (2005). Weathering of the Ganga alluvial plain, northern India: Implications from fluvial geochemistry of the Gomati River. Appl. Geochem. 20, 1-21.

Trần Đức Lương, Nguyễn Xuân Bao, (1988). Bản đồ Địa chất Việt Nam, tỷ lệ 1:500,000. Cục Địa chất và Khoáng sản Việt Nam, Hà Nội.

Trần Văn Trị, Vũ Khúc, (2009). Địa chất và Tài 
nguyên Việt Nam. Nhà xuất bản Khoa học Tự nhiên và Công nghệ, 390tr.

Vital, H., Stattegger, K., (2000). Major and trace elements of stream sediments from the lowermost Amazon River. Chem. Geol. 168, 151-168.

Wan, S., Li, A., Clift, P. D., Stuut, J. B. W., (2007). Development of the East Asian monsoon: Mineralogical and sedimentologic records in the northern South China Sea since 20 Ma. Palaeogeogr. Palaeoclimatol. Palaeoecol. 254,
561-582.

Wang, H., Liu, Z., Edlic, S., Colin, C., L. I., J., Zhao, Y., (2011). Chemical weathering in Malay Peninsula and North Borneo: Clay mineralogy and element geochemistry of river surface sediments. Sci. China Earth Sci. 54, 272-282.

Wei, G., Li, X. H., Liu, Y., Shao, L., Liang, X., (2006). Geochemical record of chemical weathering and monsoon climate change since the early Miocen in the South China Sea. Paleoceanography 21, 1-11. 